\title{
COMPARISON BETWEEN PRESCRIPTION OF REGULAR OR ON-DEMAND IBUPROFEN ON POSTOPERATIVE PAIN AFTER SINGLE-VISIT ROOT CANAL TREATMENT OF TEETH WITH IRREVERSIBLE PULPITIS
}

\author{
Kamal Nabhi', Ajay Chhabra ${ }^{2}$, Varun Jindal ${ }^{3}$, Damanpreet ${ }^{4}$, Simran Pal Singh ${ }^{5}$, \\ ${ }^{1}$ PG Student, Department of Conservative Dentistry \& Endodontics, Bhojia Dental College \& Hospital, H.P., India. \\ ${ }^{2}$ Professor and Head, Department of Conservative Dentistry \& Endodontics, Bhojia Dental College \& Hospital, H.P., India \\ ${ }^{3}$ Reader, Department of Conservative Dentistry \& Endodontics, Bhojia Dental College and Hospital, H.P., India \\ ${ }^{4}$ Reader, Department of Conservative Dentistry \& Endodontics, Bhojia Dental College and Hospital, H.P., India \\ ${ }^{5}$ PG Student, Department of Conservative Dentistry and Endodontics, Bhojia Dental College \& Hospital, H.P., India
}

\begin{abstract}
ב-

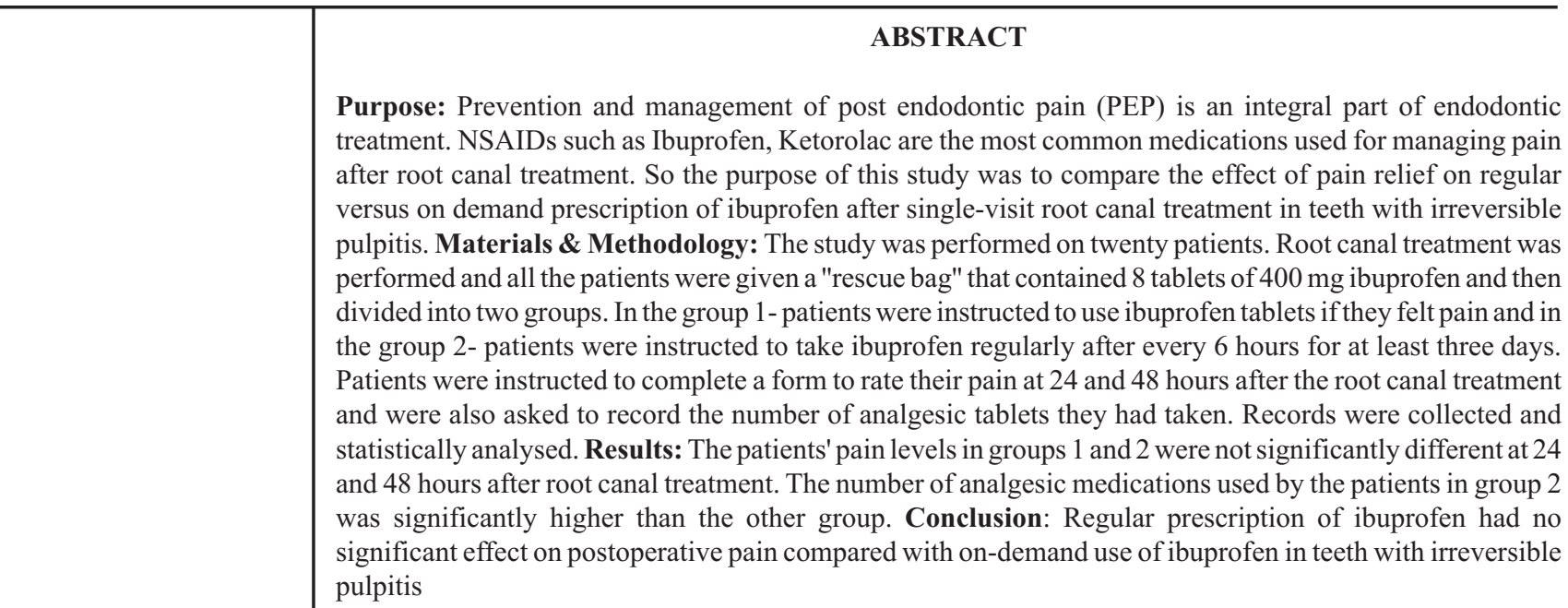

Keywords: Single Visit Root Canal Treatment, Pain, Ibuprofen, Irreversible Pulpitis, Analgesics, NSAIDs

\section{INTRODUCTION}

Pain is an unpleasant sensation that can significantly interfere with the person's quality of life and general functioning. The incidence of postoperative pain after root canal treatment has been reported to be between $3 \%$ and $58 \%$. Pain control during and after root canal treatment is an important aspect of endodontic practice. ${ }^{2}$ There are several factors associated with pain after root canal treatment-Preoperative

Corresponding Author: Kamal Nabhi

E-mail:

kamalnabhi@gmail.com Received: $5^{\text {th }}$ January 2016

Accepted: $3^{\text {rd }}$ April 2016

Online: $2^{\text {nd }}$ May 2016 factors like acute exacerbation of chronic lesion, non-vital tooth, unusual canal anatomy, periapical cysts and abscess are responsible for more flare-ups and pain. Intraoperative factors like working without rubber dam isolation, irritating canal medications and irrigation, apical extrusion of filling materials and instruments, procedural complications, and missed canals. Post-operative factors like leaky temporary and permanent filling material and lack of postoperative medicament placement. $^{3}$ All these factors can give rise to more pain. Pain experienced as a result of pulpal or periapical insult is often attributed to inflammation. Elevated tissue concentrations of prostaglandins are responsible for initiating pain and also vasodilation which is seen clinically as erythema and edema. ${ }^{4}$ The biological 
reason "why pulpectomies reduce pain is based on reducing tissue levels of inflammatory mediators. ${ }^{5}$ Informing patients about expected postendodontic pain (PEP) and prescribing medications to manage it can increase patient confidence in their dentists, increase patients' pain threshold, and improve their attitude toward future dental treatment. ${ }^{6,7}$ Non Steroidal Antiinflammatory drugs (NSAIDs) are widely available, they prevent the production of inflammatory mediators involved in producing pain, such as prostaglandins owing to pulpal inflammation and necrosis and thus they have been reported to be effective for managing pulp and periradicular pain. ${ }^{1}$ Ibuprofen has been considered a representative NSAID on the basis of its efficacy for postoperative relief of dental pain. ${ }^{8}$ Numerous investigations have been performed to evaluate the efficacy of various pain management strategies as well as the influence of various techniques, medicaments, irrigants, analgesics, anesthetic agents, and postoperative factors on the amount of postoperative pain after root canal treatment. ${ }^{9}$ Several investigations are being conducted these days in the medical field to confirm the benefits of prescribing analgesics on regular basis compared with the ondemand basis. So the aim of this study was to compare the effect on pain relief of on-demand versus regular prescription of ibuprofen after single-visit root canal treatment in teeth with irreversible pulpitis.

\section{MATERIALS \& METHODOLOGY}

Approval for the study had been granted from Ethical Committee. The following inclusion and exclusion criteria were used for this study. Exclusion Criteria were 1) Patients under 18 years of age 2) Presence of any systemic disorders or sensitivity that prevented the use of ibuprofen, 3) Gastric diseases, 4) Presence of a periapical radiolucency, 5) Pregnancy, 6) Patients having a tooth not suitable for restoration, or having serious periodontal disease that rendered the tooth unsuitable for endodontic treatment 7) Patients with spontaneous pain who needed emergency treatment, 8) Patients with teeth with tenderness to percussion and palpation, 9) Patients who had used any type of analgesic medication in the preceding 12 hours before the treatment and 10) Patients with teeth with a necrotic infected pulp or teeth with swelling.
Inclusion criteria were 1) Healthy patients with a first or second mandibular or a maxillary molar tooth with acute irreversible pulpitis and normal periapical radiographic appearance without sensitivity to percussion. 2) A positive response to an electric pulp test which confirmed the clinical diagnosis of acute irreversible pulpitis for each tooth.

Twenty patients were eligible to participate in this prospective clinical study. All patients were treated in the postgraduate clinic of the Department of Conservative Dentistry and Endodontics of Bhojia Dental College \& Hospital Budh, Baddi (H.P) from August 2014 to October 2014. Informed consent of all subjects was obtained after the nature of the procedure and the possible discomforts and risks had been fully explained to the patients. The tooth was anaesthetized. All the treatment was performed under rubber dam isolation. An access cavity was prepared, patency of canal was checked with 10 No. K file and by using electronic apex locator ROOT ZX (Morita Corporation, Kyoto, Japan), working length was determined $1 \mathrm{~mm}$ short of the apex, which was also confirmed with periapical radiographs. Teeth were excluded if there was any overestimation of the working length, inadvertent over instrumentation through the apical foramen, or extension of the root filling material beyond the working length. Initially, the root canals were instrumented to file size 15 No. K file followed by the use of Gates Glidden drills sizes 2 and 3 to prepare the coronal portion of the canals. Biomechanical Preparation was done in crown down technique using Hero Shaper Rotary instruments up to size 30/0.04 file. Irrigation was done with a $2.5 \%$ solution of sodium hypochlorite followed by normal saline between instrumentation of the canals. The root canals were then dried with paper points and obturated using lateral condensation technique using $\mathrm{AH}$ Plus sealer. Patients were instructed to complete a form (Figure1) to rate their pain at 24 and 48 hours after the root canal treatment. The following criteria were outlined for the patients to rate their pain:

0: No pain
1: Mild pain

2: Moderate pain

3: Severe pain 
All patients were randomly divided into 2 groups of 10 each. The patients were given a "rescue bag" that contained 8 tablets of $400 \mathrm{mg}$ ibuprofen. Based on the group to which they were allotted for the method of analgesic use was described to the patient. Patients in group 1 were instructed to use analgesic tablets from the rescue bag if they felt pain, whereas the patients in group 2 were instructed to regularly use the analgesic every 6 hours for three days. The patients in both groups were required to record the number of analgesic tablets they had taken on their forms. To be sure that the patients completed the forms, the patients were telephoned at 24 and 48 hours postoperatively to remind them to fill out the forms. Data was collected and was statistically analyzed.

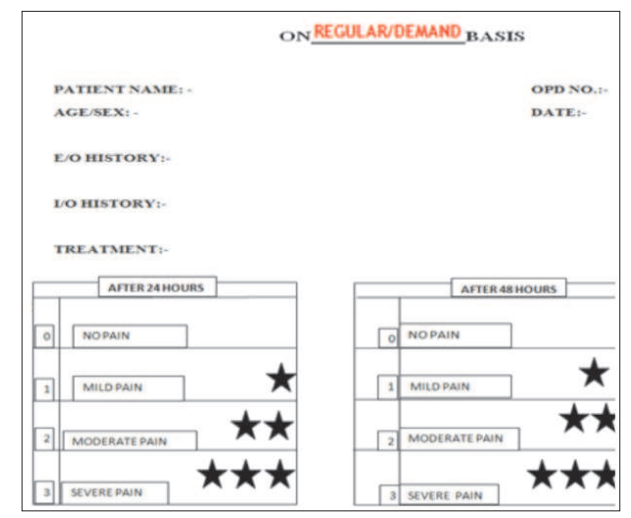

Figure 1: Patient form for rating the pain scale

\section{RESULTS}

- The number of analgesic medications used by the patients in group 2 was significantly higher than for the patients in group 1. (Figure 2)

- The patient's pain levels in groups 1 and 2 were not significantly different at 24 and 48 hours after root canal treatment (Figure 3, 4\&5).

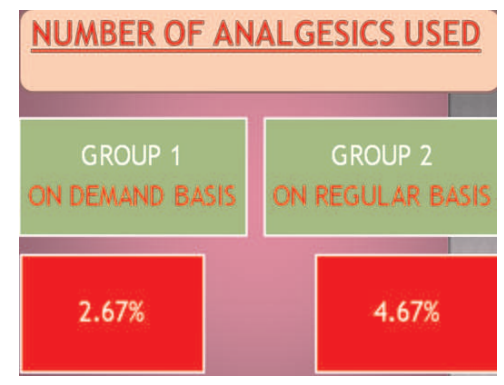

Figure 2: Number of analgesics used by the patients in both the groups

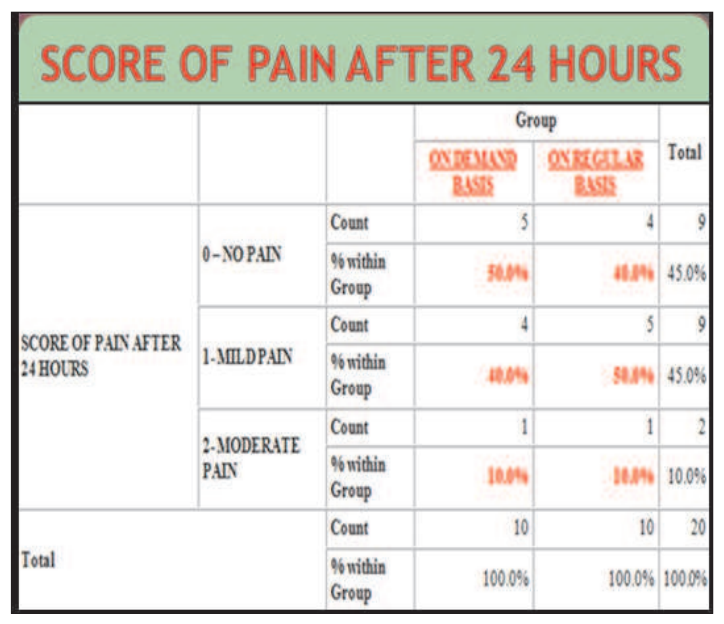

Figure 3: Pain Score after 24 hours

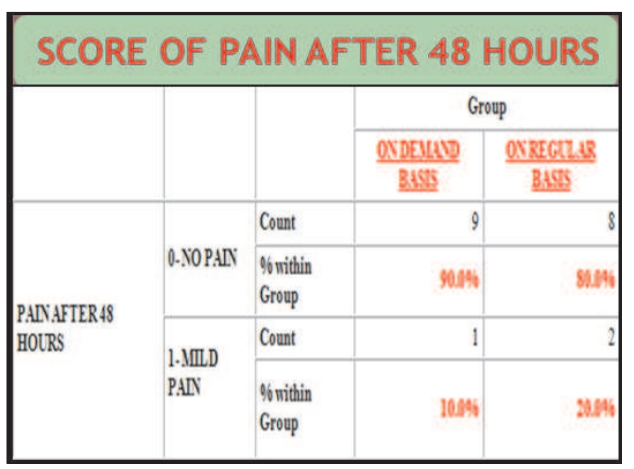

Figure 4: Pain Score after 48 hours

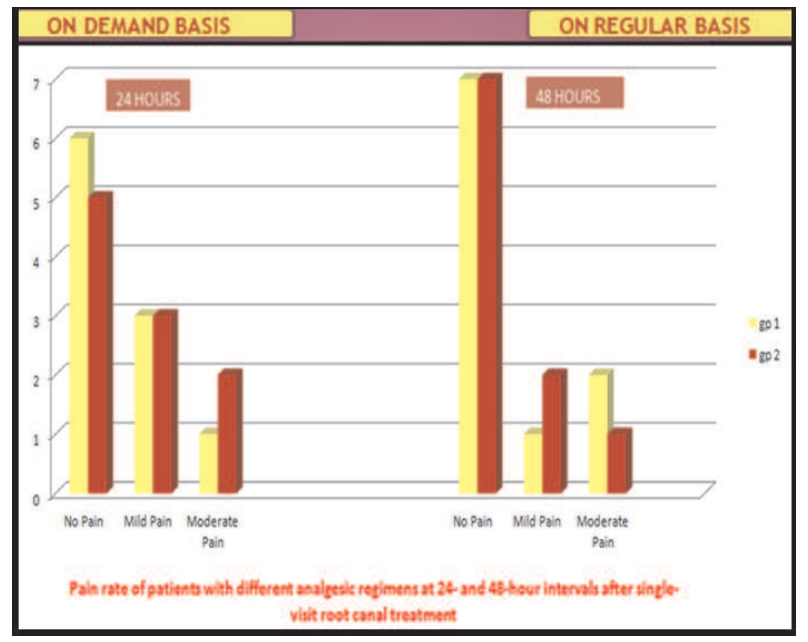

Figure 5: Graph depicting the pain rate of patients with analgesic regimens at 24 and 48 hour intervals after single visit root canal treatment

\section{DISCUSSION}

The results of the present study showed that the prescription of regular or on-demand use of $400 \mathrm{mg}$ ibuprofen had no significant influence on the level of 
pain reported by patients after single-visit root canal treatment in teeth with irreversible pulpitis for up to 48 hours after treatment. Each clinician should evaluate the benefits and the risks of prescribing medications after root canal treatment. ${ }^{10}$ NSAIDs have several known side effects such as gastrointestinal injury, peptic ulceration, and cardiovascular and thrombotic problems; for these reasons, the prescription of this medication should be done with caution. ${ }^{11,12}$ For each practitioner, it is always desirable to make treatment decisions based on evidence-based investigations. ${ }^{13}$ The results of the present study showed that for teeth with irreversible pulpitis with no spontaneous moderate to severe preoperative pain, there was no significant difference on postoperative pain reported by patients after using either on-demand or regular $400 \mathrm{mg}$ ibuprofen. The results of this study also showed that patients in group 1 who used on-demand analgesic medications consumed significantly lower numbers of ibuprofen tablets for their pain relief compared with the patients who used regular medication during the first 48 hours after treatment. Because the pain reported by the patients in both groups was not significantly different and most people prefer to use less medication after treatment, it can be assumed that it is not necessary to recommend regular use of medication after single-visit root canal treatment in patients with teeth with irreversible pulpitis. Pak JG et $\mathrm{al}^{14}$ showed that a substantial decrease in pain felt by patients during the first 2 days after root canal treatment, therefore, in the present study, the patients were asked to report their pain up to 48 hours after treatment. Su Y et al $^{15}$, Roane $\mathrm{JB}$ et $\mathrm{al}{ }^{16}$, Fox $\mathrm{J}$ et $\mathrm{al}^{17}$ Yingying Su et $\mathrm{al}^{18}$ compared the effect of the number of treatment visits on pain after root canal treatment and reported that patients who had single-visit root canal treatment felt significantly less postoperative pain compared with 2-visit treatment so in the present study, single-visit root canal treatment was performed for all patients. NSAIDs have been recommended as the first choice of analgesics after root canal treatment. Among the NSAIDs, ibuprofen has been known as the prototype medication for postoperative pain relief after root canal treatment. In the present study, ibuprofen was used as the prescribed medication after treatment as Attar S et $\mathrm{al}^{19}$ and Parirokh et $\mathrm{al}^{20}$ used ibuprofen in their studies for evaluation of pretreatment analgesia and endodontic treatment for postoperative endodontic pain. The term "flare-up" is often defined in studies of postoperative pain after root canal treatment when pain, swelling, or both occur after root canal treatment, and this forces the patient to call the dental office for an unscheduled visit to solve the patient's problem. ${ }^{21}$ The ceiling effect of ibuprofen is reported to be about $400 \mathrm{mg}$, and increasing the dose of the analgesic was not shown to significantly increase its analgesic efficacy. ${ }^{22}$ Therefore, in the present study, 400 mg ibuprofen was prescribed for each dose. The root canal filling technique may have a significant influence on postoperative pain after single-visit root canal treatment. ${ }^{23}$ Cold lateral condensation was used as the method of obturation in this study as Alonso-Ezpeleta Lo et $\mathrm{al}^{24}$ evaluated that cold lateral condensation was associated with the least amount of pain compared with the other techniques. The lack of a control group may be seen as a shortcoming for the present study. In conclusion, the regular prescription of ibuprofen had no significant effect on postoperative pain compared with on-demand use of ibuprofen in teeth with irreversible pulpitis.

\section{REFERENCES}

1. Krishnaprasada L, Jayanth M Nambiar. A Comparative evaluation of the Efficacay of two oral medication on post operative pain following single visit root canal therapy - An in vivo study. Int J Med Sci 2013;5(2): 01-04.

2. Rosenberg PA. Clinical strategies for managing endodontic pain. Endod Topics. 2002;3:78-92.

3. Masoud Parirokh, Mohammad Hosein Yosefi, Nouzar Nakhaee, Hamed Manochehrifar, Paul V. Abbott and Farshid Reza Forghani. Effect of Bupivacaine on Postoperative Pain for Inferior Alveolar Nerve Block Anesthesia after Single-visit Root Canal Treatment in Teeth with Irreversible Pulpitis. J Endod 2012;38(8):1035-1039.

4. Hersh EV, Moore PA, Ross GL. Over-the-counter analgesics \& antipyretics: a critical assessment. Clin Ther 2000; 22(5):500548.

5. Fox J, Atkinson JS, Dinin AP, Greenfield E, Hechtman E, Reeman CA. Incidence of pain following one-visit endodontic treatment. Oral Surg Oral Med Oral Pathol 1970; 30(1):123130 .

6. A. J. van Wijk and J. Hoogstraten. Reducing fear of pain associated with endodontic therapy. Int Endod J 2006;5(39):384-388. 
7. M. P. M. A. Duyx and A. J. van Wijk. The effect of written information on pain experience during periodontal probing. $\mathrm{J}$ Clin Periodontol 2004;31(4):282-285.

8. Pozzi A, Gallelli L. Pain Management for Dentists: The Role of Ibuprofen. Ann Stomatol (Roma) 2011; 2(3-4 Suppl): 3-24.

9. Moore PA, Dunsky JL. Bupivacaine anesthesia: a clinical trial for endodontic therapy. Oral Surg Oral Med Oral Pathol 1983;55:176-179.

10. Keiser K, Byrne BE. Endodontic pharmacology. In: Hargreaves KM, Cohen S, eds.Pathways of the Pulp, 10th ed. St Louis: Mosby Elsevier; 2011:671-690.

11. Ong HT, Ong LM, Tan TE. Cardiovascular effects of common analgesics. Med J Malaysia 2013; 68:189-194.

12. Sinha M, Gautam L, Shukla PK. Current perspectives in NSAID-induced gastropathy. J Ir Med Sci.2013:258-209.

13. Torabinejad M, Bahjri K. Essential elements of evidencedbased endodontics: steps involved in conducting clinical research. J Endod 2005; 31(8):563-569.

14. Pak JG, White SN. Pain prevalence and severity before, during, and after root canal treatment: a systematic review. J Endod 2011;37:429-438.

15. Su Y, Wang C, Ye L. Healing rate and post-obturation pain of single- versus multiple visit endodontic treatment for infected root canals: a systematic review. J Endod 2011;37:125-132.

16. Roane JB, Dryden JA, Grimes EW. Incidence of postoperative pain after single- and multiple-visit endodontic procedures. Oral Surg Oral Med Oral Pathol. 1983;55(1):68-72.

17. Fox J, Atkinson JS, Dinin AP. Incidence of pain following onevisit endodontic treatment. Oral Surg Oral Med Oral Pathol1970;30:123-30.
18. Yingying Su, Chenglin Wang and Ling Ye. Healing Rate and Post-obturation Pain of Single- versus Multiple-visit Endodontic Treatment for Infected Root Canals: A Systematic Review. J Endod 2011;37(2):125-132.

19. Attar S, Bowles WR, Baisden MK, Hodges JS, McClanahan SB. Evaluation of pretreatment analgesia and endodontic treatment for postoperative endodontic pain. J Endod 2008;34(6):652-655.

20. Parirokh M, Rekabi AR, Ashouri R, Rekabi AR. Effect of occlusal reduction on postoperative pain in teeth with irreversible pulpitis and mild tenderness to percussion. $\mathrm{J}$ Endod 2013;39:1-5.

21. Torabinejad M, Bahjri K. Essential elements of evidencedbased endodontics: steps involved in conducting clinical research. J Endod 2005;31:563-9.

22. Su Y, Wang C, Ye L. Healing rate and post-obturation pain of single- versus multiplevisit endodontic treatment for infected root canals: A systematic review. J Endod 2011;37:125-32.

23. Sathorn C, Parashos P, Messer H. The prevalence of postoperative pain and flare-up in single- and multiple-visit endodontic treatment: A systematic review. Int Endod J.2008;41:91-9.

24. Alonso-Ezpeleta LO, Gasco-Garcia C, Castellanos-Cosano L. Post-operative pain after one-visit root-canal treatment on teeth with vital pulps: comparison of three different obturation techniques. Med Oral Patol Oral Cir Bucal 2012;17(4):721-7. 